\title{
Roles of MOV10 in Animal RNA Virus Infection
}

\author{
Feng Su*, Xueming Liu and Yunliang Jiang* \\ Shandong Provincial Key Laboratory of Animal Biotechnology and Disease Control and Prevention, College of Animal \\ Science and Veterinary Medicine, Shandong Agricultural University, Tai'an, China
}

Animal epidemic diseases caused by RNA viruses are the primary threat to the livestock industry, and understanding the mechanisms of RNA virus clearance from target cells is critical to establish an effective method to reduce economic losses. As an SF-1, ATP-dependent RNA helicase in the UPF1p family, MOV10 participates in the RNA degradation of multiple viruses mediated via miRNA pathways and therefore contributes to a decrease in the replication of RNA viruses. This review primarily focuses on the bioactivity of MOV10, the mechanism of RNA virus removal, and the potential roles of MOV10 in RNA virus clearance. In addition, clues are provided to reduce animal diseases

OPEN ACCESS

Edited by:

Lester J. Perez,

University of Illinois at Urbana-Champaign, United States

Reviewed by:

Andrii Slonchak,

The University of

Queensland, Australia

Francisco Rivera-Benítez, Instituto Nacional de Investigaciones Forestales, Agrícolas y Pecuarias (INIFAP), Mexico

*Correspondence: Feng Su

suf@sdau.edu.cn Yunliang Jiang

yljiang723@aliyun.com

Specialty section: This article was submitted to Veterinary Infectious Diseases,

a section of the journal

Frontiers in Veterinary Science

Received: 04 June 2020

Accepted: 14 August 2020 Published: 16 September 2020

Citation:

SU F, Liu X and Jiang Y (2020) Roles of MOV10 in Animal RNA Virus Infection.

Front. Vet. Sci. 7:569737.

doi: 10.3389/fvets.2020.569737 caused by RNA viruses.

Keywords: animal RNA virus, antivirus mechanism, MOV10, miRNA pathways, mRNA

Animal epidemic diseases caused by RNA viruses are the primary threat to the livestock industry (1), and understanding the mechanisms of RNA virus clearance in target cells can lead to an effective method to reduce economic losses. Therefore, this review focuses on the current understanding of the mechanisms of viral resistance to RNA viruses that cause animal diseases.

\section{DISEASES CAUSED BY RNA VIRUSES IN THE LIVESTOCK INDUSTRY}

Animal epidemic diseases are the primary threat to the livestock industry. Of the veterinary pathogens that cause these diseases, viruses are responsible for approximately half of the most important animal diseases, according to the OIE's (Office of International Epizootic) classification of terrestrial and aquatic notifiable animal diseases (1). Animal viruses are divided into DNA and RNA viruses on the basis of the genetic materials, both the viruses are the dominate pathogens that affecting animal production in livestock industry $(1,2)$. The differences between DNA and RNA viruses include their lifetimes in target cells, how they attach to and enter host cells, and their biosynthesis, maturation, and release from cells $(2,3)$.

Compared with DNA viruses, RNA viruses have a higher mutation rate and cause more serious economic damage in the livestock industry (4). Lower mutation rates of DNA viruses were usually influence by the viral genome and DNA repairing protein that benefit for proofread and correct replication errors (5). Oppositely, offspring of RNA viruses are usually produced $1 \pm 2$ mutations compared with their parent. RNA virus usually producing a mutant cloud of descendants in extremely environment (5). RNA viruses are also divided into avian, mammalian, and zoonotic viruses in domestic animal industries. For example, the avian leukosis retrovirus causes great losses in the avian industry and many subgroups have been isolated in recent years (6-12). In mammals, more RNA viruses are also being reported, of which the classical swine fever virus and porcine reproductive and respiratory syndrome virus (PRRSV) are the main RNA viruses that cause great 
losses in porcine industries. Because of their high mutation rates and the additional subgroups identified in recent years (13-17), both viruses are difficult to eliminate. Some RNA viruses not only infect animals but also humans, with the influenza virus the most typical RNA zoonotic virus. For example, H5N1 and H9N2 subgroups of the influenza virus are the main infectious pathogens affecting both humans and animals (18-23). To reduce economic losses in animal industries, the main approaches are to reduce the virus titer in animals and to improve their immunity. Thus, an understanding of the mechanism that clears RNA viruses from target cells is the most important step in controlling virus infection.

\section{MIRNA PATHWAYS ARE IMPORTANT IN THE CLEARANCE OF ANIMAL RNA VIRUSES}

RNA interference (RNAi) is an important mechanism in mediating the clearance of RNA viruses (24). Viral RNA can be degraded through the inhibition of viral replication by the binding effects between small interfering RNAs and viral nucleic acids $(24,25)$. Generally, the antiviral effects due to RNAi are typically found in invertebrates, and RNAi functioning as an antiviral effector has only been detected in undifferentiated stem cells $(26,27)$. RNAi also plays important roles in the activation of IFN-I (Type I interferon) and its antiviral effectors (IFNstimulated genes), with those genes producing the main antiviral effects in differentiated vertebrate somatic cells (Figure 1) (28).

RNA virus replication and clearance are typically influenced by several factors, of which miRNAs produced in cells may play important roles in a regulated network. miRNAs usually bind to the miRNA binding sites within mRNAs and viral genomes to exert their regulatory function $(29,30)$. The number of miRNA binding sites within a viral genome affects the viral replication (Figure 1). Most miRNA binding sites are in the 5' and $3^{\prime}$ non-translation regions (NTRs) of a viral genome (31), but the sites were also recently found in the translated regions $(32,33)$. An increase in the number of perfect complementary miRNA binding sites in the NTRs of RNA viruses causes strong translational repression in vitro and a decrease in virulence in mice (34). miRNA gene translation is also influenced by epigenetic and environmental conditions $(34,35)$. For example, compared with primary tissues, low levels of miRNAs are detected in cultural cells, especially in a high confluency (36). Furthermore, non-canonical miRNA target sites in specific cells are also potential factors that affect miRNA production and therefore RNA virus replication (25).

Direct inhibition effects of miRNAs on viruses were previous recognized as an effective way in invertebrates rather than in vertebrates, subsequent studies confirmed the anti-viral function of miRNAs in undifferential vertebrates' stem cells. But the direct viral inhibition effect of miRNAs was controversial in somatic Cells (37). Cullen's studies evaluated the directly viral genome targeting effects of miRNAs and his research revealed viruses induced miRNAs are hardly causing reduction of virus copy number (38-40). Recently study summarized the potential directly viral genome targeting effects of miRNAs. Trobaugh's review analyzed the direct inhibitory effects of miRNAs. And the review point out that direct inhibitory effects of miRNAs on viruses are primarily concentrated in the viral genome and in viral genome translation (Figure 1) $(31,41)$. There are so many reasons causing direct targeting reduction of miRNAs, of which viruses escaping mechanism, incomplete pairing of miRNA and viruses mutation are the important reasons. But the artificial application of miRNAs on viruses genome were reported as an important method to reduce viral replication copies recently.

Direct inhibitory effects of miRNAs on viruses mainly play its roles in viral genome and in viral genome translation. Positivestrand RNA viruses release their genomes into the cytoplasm after entering cells following recognition by receptors within the membrane surface (41). Similar to mRNA produced in a cell, the released viral RNA is either decayed or replicated when combined with miRNAs in the cytoplasm. For example, the expression of miR-181, miR-206, miR-23, and miR-378 in specific cells can inhibit the replication of PRRSV by binding to the viral genome $(42,43)$. By contrast, miR-17 and let-7c bind to the 3' NTR of the bovine viral diarrhea virus genome and cause virus genome translation and an increase in RNA stability rather than translational repression (41). Similar effects are also found in negative-strand viruses. The negative-stand RNA released in the cytoplasm is first translated into positive-stand RNA for protein synthesis and virus assembly. The translated positive RNA can recruit miRNA binding to the miRNA-recognized sites and ultimately influence virus replication and assembly (25). For example, the influenza PB1 gene recruits miR-323, miR491, miR-485, miR-654, and miR-3145, which leads to RNA degradation in infected human and canine epithelial cell lines in vitro $(33,44,45)$.

To determine the indirect effects of miRNAs on virus infection, the primary focus is on the level of miRNAs and the changes in host immunity response in target cells (Figure 1) (46). Specifically, an immune response initiated by a virus mediates viral-recognition receptors that lead to activation of translation factors and ultimately changes in the expression profiles of miRNAs $(47,48)$. For example, changes in the expression of specific miRNAs (miR-151-5p and miR-223-3p) determine whether the H5N2 influenza virus is pathogenic or is attenuated (49). Changes in specific miRNAs also affect miRNAmediated protein expression (50). The IFN systems are a crucial mechanism in the removal of viral infection (25). Virus-mediated regulation of the IFN signaling cascade is controlled by miRNA levels in target cells (25). For example, miR-23 and miR-505 can increase IFN- $\alpha / \beta$ expression, which is useful in clearing PRRSV $(42,43)$. By contrast, with the expression of miR-23b, avian leukosis viral infection in chicken spleen downregulates IFN regulatory factor 1 levels and innate immune induction (51). Thus, the miRNAs that are involved in downregulating the innate immune response during RNA virus infections need to be identified in the future.

Though the indirect effects of miRNAs on RNA viral infection were widely confirmed and recognized, the direct effects of miRNAs were still controversial. This controversy was mainly concentrated on several factors. Firstly, miRNAs were reducible 


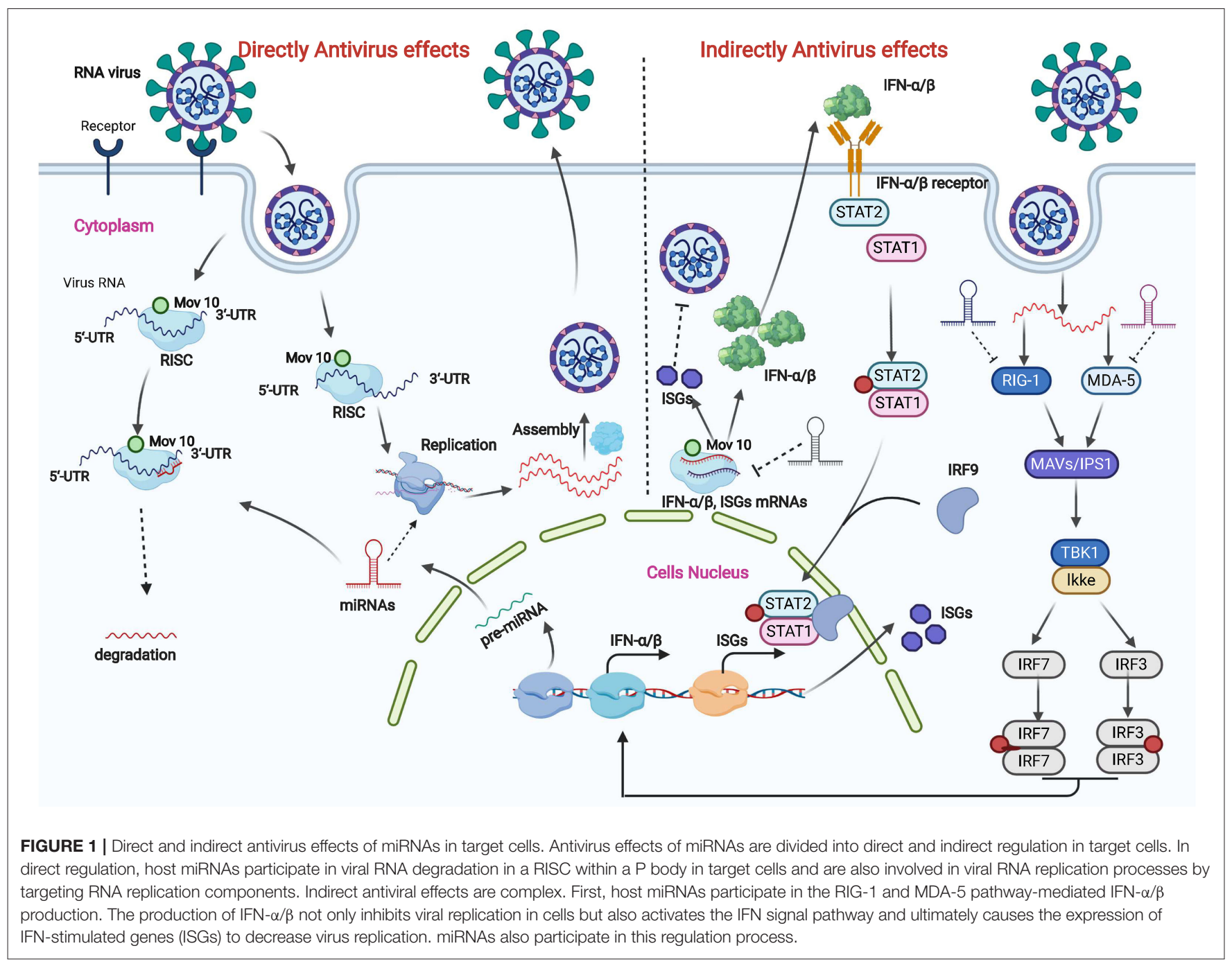

generated from the cells after the viruses infection, but these miRNAs were hardly presented its' directly target effects on viral genome because of the low level of miRNAs produced by the target cells. The other factor is the potential escaping mechanism of viral and the cells complex immune system. The mismatch of miRNAs and viral genome mutation also reduced its inhibition effects.

\section{MOV10 IS AN IMPORTANT REGULATOR OF ANIMAL RNA VIRUS INVASION}

MOV10 is an important SF-1, ATP-dependent RNA helicase in the UPF1p family (52-55), originally identified as a protein that prevents Moloney murine leukemia virus infection in mice. Two potential mechanisms can explain the antiviral bioactivity of MOV10: (1) regulating antiviral gene expression so as to achieve antiviral capacity (56) and (2) changing miRNA expression directly or indirectly so as to mediate viral clearance effects (46). The two mechanisms are discussed below in detail.

\section{MOV10 Regulates Antiviral Gene Expression by Different Pathways}

The antiviral activity of MOV10 has been evaluated and detected in many studies. The infectivity of different viruses is regulated by the MOV10 helicase, for example, human hepatitis delta virus (57), human immunodeficiency virus type 1 (HIV-1), and dengue virus (58). The same effect is also observed with PRRSV infection (59). Different genes and pathways are activated in specific virusinfected target cells. In HIV-infected cells, the antiviral activity of MOV10 is detected in multiple stages in original studies. MOV10 is efficiently incorporated into virions and reduces virus infectivity by inhibiting reverse transcription in the first stage (52). Overexpression of APOBEC3G and MOV10 reduces proteolytic processing of HIV-1 Gag, which effectively reduces HIV replication in the later stage (60). Recent studies show that MOV10 inhibits the degradation of APOBEC3G through interfering with the Vif-mediated (Vif: HIV-1-encoded virion infectivity factor protein) ubiquitin-proteasome pathway (6163). MOV10 can also provide antiviral activity against RNA viruses by increasing the induction of RIG-I-MAVS-independent 


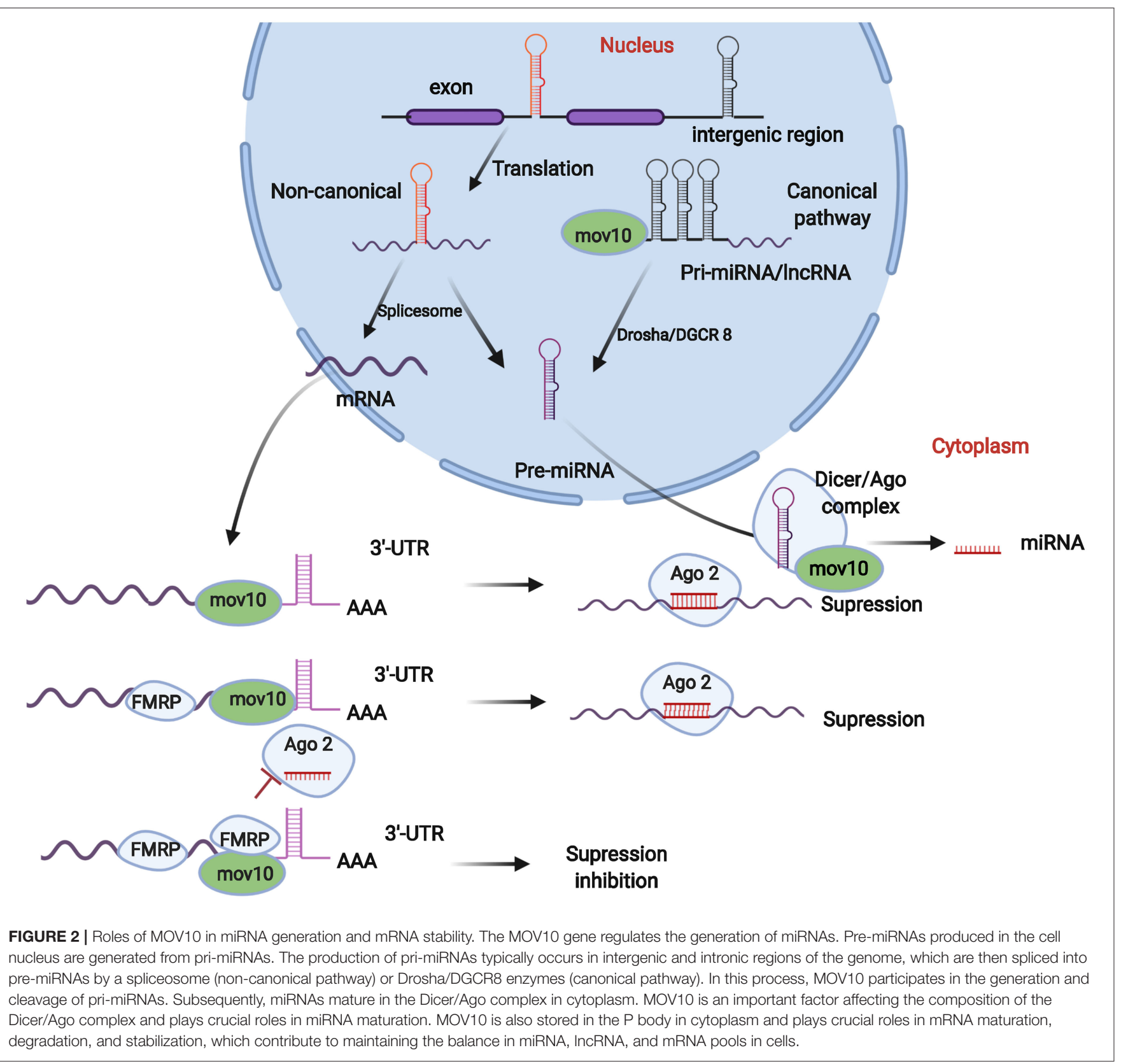

IFN (56) and through IKK $\epsilon$ and IRF3, the induction of IFN (Figure 1) (64). In influenza A virus-infected models, MOV10 with nucleoprotein (NP) promotes viral RNA degradation through the lysosomal pathway (65). In addition, MOV10 sequesters the ribonucleoprotein (RNP) of influenza A virus in the cytoplasm and is antagonized by viral influenza nonstructural (NS1) protein (66).

In a recent study of MOV10 that focused on animal disease, MOV10 directly inhibited replication of the PRRSV by retaining the viral nucleocapsid protein in the cytoplasm of Marc-145 cells (59). MOV10 also inhibits replication of the murine leukemia virus (67). Many genes potentially activated by MOV10 exhibit strong antiviral bioactivity
(58). IRAV (FLJ11286) is an interferon-stimulated gene with antiviral activity against dengue virus that interacts with MOV10 (58).

\section{MOV10 Mediates Inhibition of RNA Viruses via miRNA Pathways}

As mentioned above, MOV10 antiviral activity is expressed through the activation of different genes and pathways, of which miRNA pathway-mediated viral inhibition is important in restricting viral invasion. In the entire synthesis process of miRNAs, MOV10 not only functions in pri-miRNA production in the cell nucleus (68) but also has crucial roles in miRNA maturation and degradation (69). MOV10 also has crucial roles 
in mRNA maturation and degradation via exposure of miRNA recognition sites within mRNAs (Figure 2) (70).

The generation of pri-miRNAs and pre-miRNAs is the first step in the production of miRNAs, which is regulated by Drosha and DGCR8 enzymes and is also controlled by the MOV10 gene (71). Generally, the original pool is composed of primiRNAs and pre-mRNAs. Pre-miRNAs are typically produced in the cell nucleus by two important pathways. In the canonical pathway, pre-miRNAs are generated from exonic, intronic, or intergenic regions, followed by Drosha/DGCR8 processing to transform pri-miRNA transcripts into pre-miRNAs $(72,73)$. In the non-canonical pathway, pre-miRNAs are formed by splicing, debranching, and trimming of short introns without Drosha processing (74). In this process to form pre-miRNAs, MOV10 typically binds splicing factors, such as SRSF1 and DDX5 $(68,75)$, forming a splicing complex, which completes the pre-mRNA and pri-miRNA splicing process after binding intronic regions (Figure 2).

The pre-miRNAs generated from the canonical and noncanonical pathways are exported from the nucleus via Exportin 5 and then cleavage by Dicer occurs within the RISC loading complex (RLC) (76). Then, the miRNA/miRNA duplex unwinds via the Argonaute complex. In this process, MOV10 typically combines with Dicer, Ago, and TRBP (transactivation response element RNA-binding protein) forming the RISC complex and finally promoting miRNA maturation (76). Thus, MOV10 deficiency could cause an imbalance in the pools of miRNA, mRNA, and lncRNA (long non-code RNA) (Figure 2).

MOV10 is also important in the regulation of mRNA degradation and stability. A MOV10 protein, typically in the cytoplasm, combines with an Argonaute protein to form a complex that was recognized as an important component stored in a mRNA processing body (the P body) (60). In a previous study $(60,66)$, MOV10 inhibited retrotransposition by binding cell ribonucleoprotein particles (RNPs). MOV10 can bind high GC regions of the 3'-UTR within mRNAs, exposing miRNA recognition sites and guiding Ago proteins in promoting mRNA degradation (60). MOV10 can also increase mRNA stability and maturity via enriching the Fragile $\mathrm{X}$ mental retardation protein (FMRP) in miRNA-recognized sites (Figure 2) (66).

\section{REFERENCES}

1. Alejandro B. Vaccines and vaccination for veterinary viral diseases: a general overview. In Vaccine Technologies for Veterinary Viral Diseases. New York, NY: Springer (2016). p. 1-24.

2. Roy P. Bluetongue virus proteins and particles and their role in virus entry, assembly, and release. Adv Virus Res. (2005) 64:69-123. doi: 10.1016/S0065-3527(05)64004-3

3. Steinhauer DA, Holland J. Rapid evolution of RNA viruses. Annu Rev Microbiol. (1987) 41:409-31. doi: 10.1146/annurev.mi.41.100187.002205

4. Lauring AS, Frydman J, Andino R. The role of mutational robustness in RNA virus evolution. Nat Rev Microbiol. (2013) 11:327-36. doi: $10.1038 /$ nrmicro3003

5. Duffy S. Why are RNA virus mutation rates so damn high? PLoS Biol. (2018) 16:e3000003. doi: 10.1371/journal.pbio.3000003
The virulence and infectivity of RNA viruses are influenced by MOV10-mediated changes in miRNA/mRNA. In the third stage of HIV infection, HIV infectivity is weakened because of miRNA expression in target cells (63). MOV10 also serves as a cofactor of HIV-1 Rev to facilitate Rev/RRE-dependent nuclear export of viral mRNAs (77). The same influence of MOV10 is apparent in the replication of human hepatitis delta virus (57). MOV10 can also weaken influenza infectivity and inhibit influenza A virus replication via binding $\operatorname{RNP}(65,78)$.

\section{CONCLUSIONS}

The antiviral activity of MOV10 during RNA virus infection is discussed in this review. Overall, the antiviral capacity of MOV10 is primarily reflected in two important mechanisms. First, MOV10 weakens viral virulence by binding the related protein, thereby activating IFN signal and cell autophagy pathways. Second, MOV10 functions as an RNA helicase during RNA virus infection. MOV10 regulates miRNA and mRNA generation, maturation, and degradation by miRNA pathways, which influence virus replication and packaging. The two mechanisms are typically coordinated in different virus infection stages. In addition, the number of studies is increasing that confirm MOV10 not only has important roles in infection by human viruses, such as HIV and human hepatitis delta virus, but also shows antiviral activity against animal RNA viruses. The antiviral ability of MOV10 and the related pathways during animal RNA virus infection are worthy of future attention. It is also can be used as an important tools for reduction of animal RNA viruses infection in future.

\section{AUTHOR CONTRIBUTIONS}

FS, XL, and YJ conceived the study and wrote the manuscript. All authors contributed to the article and approved the submitted version.

\section{FUNDING}

This work was supported by funds from the Shandong Agricultural Breeding project (2019LZGC019) and the Grant from China Scholarship Council.

6. Li D, Qin L, Gao H, Yang B, Liu W, Qi X, et al. Avian leukosis virus subgroup A and B infection in wild birds of Northeast China. Vet Microbiol. (2013) 163:257-63. doi: 10.1016/j.vetmic.2013.01.020

7. Zhou D, Xue J, Zhang Y, Wang G, Feng Y, Hu L, et al. Outbreak of myelocytomatosis caused by mutational avian leukosis virus subgroup $\mathrm{J}$ in China, 2018. Transbound Emerg Dis. (2019) 66:622-6. doi: 10.1111/tbed.13096

8. Li J, Meng F, Li W, Wang Y, Chang S, Zhao P, et al. Characterization of avian leukosis virus subgroup J isolated between 1999 and 2013 in China. Poultry Sci. (2018) 97:3532-9. doi: 10.3382/ps/pey241

9. Su Q, Li Y, Li W, Cui S, Tian S, Cui Z, et al. Molecular characteristics of avian leukosis viruses isolated from indigenous chicken breeds in China. Poultry Sci. (2018) 97:2917-25. doi: 10.3382/ps/pex367

10. Li Y, Fu J, Cui S, Meng F, Cui Z, Fan J, et al. Gp85 genetic diversity of avian leukosis virus subgroup J among different individual chickens from a native flock. Poultr Sci. (2017) 96:1100-7. doi: 10.3382/ps/pew407 
11. Chen H, Wang Y, Zhao P, Li J, Cui Z. Acute fibrosarcomas caused by avian leukosis virus subgroup J associated with v-fps oncogene. J Anim Vet Adv. (2012) 11:2910-6. doi: 10.3923/javaa.2012.2910.2916

12. Zhao $\mathrm{P}$, Dong $\mathrm{X}$, Cui Z. Isolation, identification, and gp 85 characterization of a subgroup A avian leukosis virus from a contaminated live newcastle disease virus vaccine, first report in China. Poultr Sci. (2014) 93:2168-74. doi: $10.3382 /$ ps.2014-03963

13. Yu Y, Cai X, Wang G, Kong N, Liu Y, Xiao Y, et al. Anti-idiotypic antibodies reduce efficacy of the attenuated vaccine against highly pathogenic PRRSV challenge. BMC Vet Res. (2014) 10:39. doi: 10.1186/1746-6148-10-39

14. Wang X, Qiu H, Zhang M, Cai X, Qu Y, Hu D, et al. Distribution of highly pathogenic porcine reproductive and respiratory syndrome virus (HP-PRRSV) in different stages of gestation sows: HP-PRRSV distribution in gestation sows. Vet Immunol Immunopathol. (2015) 166:88-94. doi: 10.1016/j.vetimm.2015.06.002

15. Zhao P, Ma C-T, Cui Z-Z. Analysis of quasispecies diversity and mutations for highly pathogenic porcine reproductive and respiratory syndrome virus in china based on ORF 5 genes. J Anim Vet Adv. (2012) 11:2741-6. doi: 10.3923/javaa.2012.2741.2746

16. Gao J, Kong N, Xiao Y, Zhang A, Zhou E. Development of real-time PCR methods for the detection of CD163 and porcine reproductive and respiratory syndrome virus N genes in Marc-145 cell. J Anim Vet Adv. (2012) 11:4489-93. doi: 10.3923/javaa.2012.4489.4493

17. Zhang K, Li H, Dong S, Liu Y, Wang D, Liu H, et al. Establishment and evaluation of a PRRSV-sensitive porcine endometrial epithelial cell line by transfecting SV40 large T antigen. BMC Vet Res. (2019) 15:1. doi: 10.1186/s12917-019-2051-1

18. Xue R, Tian Y, Hou T, Bao D, Chen H, Teng Q, et al. H9N2 influenza virus isolated from minks has enhanced virulence in mice. Transb Emerg Dis. (2018) 65:904-10. doi: 10.1111/tbed.12805

19. Peng L, Chen C, Kai-yi H, Feng-xia Z, Yan-li Z, Zong-shuai L, et al. Molecular characterization of H9N2 influenza virus isolated from mink and its pathogenesis in mink. Vet Microbiol. (2015) 176:88-96. doi: 10.1016/j.vetmic.2015.01.009

20. Wei L, Cui J, Song Y, Zhang S, Han F, Yuan R, et al. Duck MDA5 functions in innate immunity against $\mathrm{H} 5 \mathrm{~N} 1$ highly pathogenic avian influenza virus infections. Vet Res. (2014) 45:66. doi: 10.1186/1297-9716-45-66

21. Lv J, Wei L, Yang Y, Wang B, Liang W, Gao Y, et al. Amino acid substitutions in the neuraminidase protein of an H9N2 avian influenza virus affect its airborne transmission in chickens. Vet Res. (2015) 46:44. doi: 10.1186/s13567-014-0142-3

22. Song Q-q, Zhang F-x, Liu J-j, Ling Z-s, Zhu Y-l, Jiang S-j, et al. Dog to dog transmission of a novel influenza virus (H5N2) isolated from a canine. Vet Microbiol. (2013) 161:331-3. doi: 10.1016/j.vetmic.2012. 07.040

23. Yao M, Zhang X, Gao J, Chai T, Miao Z, Ma W, et al. The occurrence and transmission characteristics of airborne H9N2 avian influenza virus. Berliner Munchener Tierarztliche Wochenschr. (2011) 124:136-41.

24. Ding S-W, Voinnet O. Antiviral immunity directed by small RNAs. Cell. (2007) 130:413-26. doi: 10.1016/j.cell.2007.07.039

25. Trobaugh DW, Klimstra WB. MicroRNA regulation of RNA virus replication and pathogenesis. Trends Mol Med. (2017) 23:80-93. doi: 10.1016/j.molmed.2016.11.003

26. Maillard P, Ciaudo C, Marchais A, Li Y, Jay F, Ding S, et al. Antiviral RNA interference in mammalian cells. Science. (2013) 342:235-8. doi: $10.1126 /$ science. 1241930

27. Li Y, Lu J, Han Y, Fan X, Ding S-W. RNA interference functions as an antiviral immunity mechanism in mammals. Science. (2013) 342:231-4. doi: $10.1126 /$ science. 1241911

28. Schneider WM, Chevillotte MD, Rice CM. Interferon-stimulated genes: a complex web of host defenses. Annu Rev Immunol. (2014) 32:513-45. doi: 10.1146/annurev-immunol-032713-120231

29. Grimson A, Farh KK-H, Johnston WK, Garrett-Engele P, Lim LP, Bartel DP. MicroRNA targeting specificity in mammals: determinants beyond seed pairing. Mol Cell. (2007) 27:91-105. doi: 10.1016/j.molcel.2007.06.017

30. Teterina NL, Liu G, Maximova OA, Pletnev AG. Silencing of neurotropic flavivirus replication in the central nervous system by combining multiple
microRNA target insertions in two distinct viral genome regions. Virology. (2014) 456:247-58. doi: 10.1016/j.virol.2014.04.001

31. Trobaugh DW, Gardner CL, Sun C, Haddow AD, Wang E, Chapnik E, et al. RNA viruses can hijack vertebrate microRNAs to suppress innate immunity. Nature. (2014) 506:245-8. doi: 10.1038/nature12869

32. Song L, Liu H, Gao S, Jiang W, Huang W. Cellular microRNAs inhibit replication of the H1N1 influenza A virus in infected cells. J Virol. (2010) 84:8849-60. doi: 10.1128/JVI.00456-10

33. Zheng Z, Ke X, Wang M, He S, Li Q, Zheng C, et al. Human microRNA hsa-miR-296-5p suppresses enterovirus 71 replication by targeting the viral genome. J Virol. (2013) 87:5645-56. doi: 10.1128/JVI.02655-12

34. Heiss BL, Maximova OA, Thach DC, Speicher JM, Pletnev AG. MicroRNA targeting of neurotropic flavivirus: effective control of virus escape and reversion to neurovirulent phenotype. J Virol. (2012) 86:5647-59. doi: 10.1128/JVI.07125-11

35. Davis-Dusenbery BN, Hata A. Mechanisms of control of microRNA biogenesis. J Biochem. (2010) 148:381-92. doi: 10.1093/jb/mvq096

36. Hwang H-W, Wentzel EA, Mendell JT. Cell-cell contact globally activates microRNA biogenesis. Proc Natl Acad Sci USA. (2009) 106:7016-21. doi: 10.1073/pnas.0811523106

37. Tenoever BR. RNA viruses and the host microRNA machinery. Nat Rev Microbiol. (2013) 11:169-80. doi: 10.1038/nrmicro2971

38. Cullen BR, Cherry S. Is RNA interference a physiologically relevant innate antiviral immune response in mammals? Cell Host Microbe. (2013) 14:374-8. doi: 10.1016/j.chom.2013.09.011

39. Cullen BR. How do viruses avoid inhibition by endogenous cellular microRNAs? PLoS Pathog. (2013) 9:e1003694. doi: 10.1371/journal.ppat.1003694

40. Bogerd HP, Skalsky RL, Kennedy EM, Furuse Y, Whisnant AW, Flores O, et al. Replication of many human viruses is refractory to inhibition by endogenous cellular microRNAs. J Virol. (2014) 88:8065-76. doi: 10.1128/JVI.00985-14

41. Scheel TK, Luna JM, Liniger M, Nishiuchi E, Rozen-Gagnon K, Shlomai A, et al. A broad RNA virus survey reveals both miRNA dependence and functional sequestration. Cell Host Microbe. (2016) 19:409-23. doi: 10.1016/j.chom.2016.02.007

42. Guo X-K, Zhang Q, Gao L, Li N, Chen X-X, Feng W-H. Increasing expression of microRNA 181 inhibits porcine reproductive and respiratory syndrome virus replication and has implications for controlling virus infection. J Virol. (2013) 87:1159-71. doi: 10.1128/JVI.02386-12

43. Zhang Q, Guo X-k, Gao L, Huang C, Li N, Jia X, et al. MicroRNA23 inhibits PRRSV replication by directly targeting PRRSV RNA and possibly by upregulating type I interferons. Virology. (2014) 450:182-95. doi: 10.1016/j.virol.2013.12.020

44. Khongnomnan K, Makkoch J, Poomipak W, Poovorawan Y, Payungporn S. Human miR-3145 inhibits influenza A viruses replication by targeting and silencing viral PB1 gene. Exp Biol Med. (2015) 240:1630-9. doi: $10.1177 / 1535370215589051$

45. Ingle H, Kumar S, Raut AA, Mishra A, Kulkarni DD, Kameyama T, et al. The microRNA miR-485 targets host and influenza virus transcripts to regulate antiviral immunity and restrict viral replication. Sci Signal. (2015) 8:ra126-ra. doi: 10.1126/scisignal.aab3183

46. Maillard PV, van der Veen AG, Poirier EZ, e Sousa CR. Slicing and dicing viruses: antiviral RNA interference in mammals. EMBO J. (2019) 38:e100941. doi: 10.15252/embj.2018100941

47. $\mathrm{Wu} J$, Chen $\mathrm{ZJ}$. Innate immune sensing and signaling of cytosolic nucleic acids. Annu Rev Immunol. (2014) 32:461-88. doi: 10.1146/annurev-immunol-032713-120156

48. Aguado LC, Schmid S, Sachs D, Shim JV, Lim JK. MicroRNA function is limited to cytokine control in the acute response to virus infection. Cell Host Microbe. (2015) 18:714-22. doi: 10.1016/j.chom.2015.11.003

49. Choi E-J, Kim HB, Baek YH, Kim E-H, Pascua PNQ, Park S-J, et al. Differential microRNA expression following infection with a mouseadapted, highly virulent avian H5N2 virus. BMC Microbiol. (2014) 14:252. doi: 10.1186/s12866-014-0252-0

50. Beachboard DC, Horner SM. Innate immune evasion strategies of DNA and RNA viruses. Curr Opin Microbiol. (2016) 32:113-9. doi: 10.1016/j.mib.2016.05.015 
51. Li Z, Chen B, Feng M, Ouyang H, Zheng M, Ye Q, et al. MicroRNA-23b promotes avian leukosis virus subgroup J (ALV-J) replication by targeting IRF1. Sci Rep. (2015) 5:10294. doi: 10.1038/srep10294

52. Furtak V, Mulky A, Rawlings SA, Kozhaya L, Lee K, KewalRamani VN, et al. Perturbation of the P-body component Mov10 inhibits HIV-1 infectivity. PLoS ONE. (2010) 5:e9081. doi: 10.1371/journal.pone.0009081

53. Saito K, Ishizu H, Komai M, Kotani H, Kawamura Y, Nishida KM, et al. Roles for the $\mathrm{Yb}$ body components armitage and $\mathrm{Yb}$ in primary piRNA biogenesis in Drosophila. Genes Dev. (2010) 24:2493-8. doi: 10.1101/gad.1989510

54. Haase AD, Fenoglio S, Muerdter F, Guzzardo PM, Czech B, Pappin DJ, et al. Probing the initiation and effector phases of the somatic piRNA pathway in Drosophila. Genes Dev. (2010) 24:2499-504. doi: 10.1101/gad.1968110

55. Fischer SE, Montgomery TA, Zhang C, Fahlgren N, Breen PC, Hwang A, et al. The ERI-6/7 helicase acts at the first stage of an siRNA amplification pathway that targets recent gene duplications. PLoS Genet. (2011) 7:e1002369. doi: 10.1371/journal.pgen.1002369

56. Cuevas RA, Ghosh A, Wallerath C, Hornung V, Coyne CB, Sarkar SN. MOV10 provides antiviral activity against RNA viruses by enhancing RIG-I-MAVS-independent IFN induction. J Immunol. (2016) 196:3877-86. doi: 10.4049/jimmunol.1501359

57. Haussecker D, Cao D, Huang Y, Parameswaran P, Fire AZ, Kay MA. Capped small RNAs and MOV10 in human hepatitis delta virus replication. Nat struct Mol Biol. (2008) 15:714-21. doi: 10.1038/nsmb.1440

58. Balinsky CA, Schmeisser H, Wells AI, Ganesan S, Jin T, Singh K, et al. IRAV (FLJ11286), an interferon-stimulated gene with antiviral activity against dengue virus, interacts with MOV10. J Virol. (2017) 91:e01606-16. doi: 10.1128/JVI.01606-16

59. Zhao K, Li L-W, Zhang Y-J, Jiang Y-F, Gao F, Li G-X, et al. MOV10 inhibits replication of porcine reproductive and respiratory syndrome virus by retaining viral nucleocapsid protein in the cytoplasm of Marc-145 cells. Biochem Biophys Res Commun. (2018) 504:157-63. doi: 10.1016/j.bbrc.2018.08.148

60. Burdick R, Smith JL, Chaipan C, Friew Y, Chen J, Venkatachari NJ, et al. P body-associated protein Mov10 inhibits HIV-1 replication at multiple stages. J Virol. (2010) 84:10241-53. doi: 10.1128/JVI.00585-10

61. Arjan S, Swanson C, Sherer N, Malim M. Mov10, an APOBEC3G-interacting RNA-binding protein, inhibits HIV-1 infection. Retrovirology. (2011) 8(Suppl. 2):P2. doi: 10.1186/1742-4690-8-S2-P2

62. Chen C, Ma X, Hu Q, Li X, Huang F, Zhang J, et al. Moloney leukemia virus 10 (MOV10) inhibits the degradation of APOBEC3G through interference with the Vif-mediated ubiquitin-proteasome pathway. Retrovirology. (2017) 14:56. doi: 10.1186/s12977-017-0382-1

63. Liu C, Zhang X, Huang F, Yang B, Li J, Liu B, et al. APOBEC3G inhibits microRNA-mediated repression of translation by interfering with the interaction between Argonaute-2 and MOV10. J Biol Chem. (2012) 287:29373-83. doi: 10.1074/jbc.M112.354001

64. Cuevas R, Hornung V, Coyne C, Sarkar S. MOV10 provides antiviral activity against RNA viruses by enhancing IFN induction through IKK? and IRF3 (INC8P. 441). Am Assoc Immnol. (2014) 196:3877-86.

65. Villalón-Letelier F, Reading PC. Unraveling the role of the MOV10 RNA helicase during influenza A virus infection. Biochem J. (2019) 476:1005-8. doi: 10.1042/BCJ20190018
66. Li J, Hu S, Xu F, Mei S, Liu X, Yin L, et al. MOV10 sequesters the RNP of influenza A virus in the cytoplasm and is antagonized by viral NS1 protein. Biochem J. (2019) 476:467-81. doi: 10.1042/BCJ20180754

67. Zhang Y, Hu S, Pang X, Li J, Guo F. Host factor Moloney leukemia virus 10 (MOV10) protein inhibits replication of the xenotropic murine leukemia virus-related virus (XMRV). Bing Du Xue Bao. (2014) 30:514-20.

68. Fu K, Tian S, Tan H, Wang C, Wang H, Wang M, et al. Biological and RNA regulatory function of MOV10 in mammalian germ cells. BMC Biol. (2019) 17:39. doi: 10.1186/s12915-019-0659-z

69. El Messaoudi-Aubert S, Nicholls J, Maertens GN, Brookes S, Bernstein E, Peters G. Role for the MOV10 RNA helicase in polycomb-mediated repression of the INK4a tumor suppressor. Nat Struct Mol Biol. (2010) 17:862. doi: $10.1038 / \mathrm{nsmb} .1824$

70. Liu T, Sun Q, Liu Y, Cen S, Zhang Q. The MOV10 helicase restricts hepatitis B virus replication by inhibiting viral reverse transcription. J Biol Chem. (2019) 294:19804-13. doi: 10.1074/jbc.RA119.009435

71. Winter J, Jung S, Keller S, Gregory RI, Diederichs S. Many roads to maturity: microRNA biogenesis pathways and their regulation. Nat Cell Biol. (2009) 11:228-34. doi: 10.1038/ncb0309-228

72. Kawahara H, Imai T, Okano H. MicroRNAs in neural stem cells and neurogenesis. Front Neurosci. (2012) 6:30. doi: 10.3389/fnins.2012.00030

73. Li S, Wang L, Fu B, Dorf ME. Trim65: a cofactor for regulation of the microRNA pathway. RNA Biol. (2014) 11:1113-21. doi: 10.4161/rna. 36179

74. Okamura K. Diversity of animal small RNA pathways and their biological utility. Wiley Interdiscip Rev RNA. (2012) 3:351-68. doi: 10.1002/ wrna.113

75. Goodier JL, Cheung LE, Kazazian HH Jr. Mapping the LINE1 ORF1 protein interactome reveals associated inhibitors of human retrotransposition. Nucleic Acids Res. (2013) 41:7401-19. doi: 10.1093/nar/gkt512

76. Xie M, Li M, Vilborg A, Lee N, Shu M-D, Yartseva V, et al. Mammalian 5'capped microRNA precursors that generate a single microRNA. Cell. (2013) 155:1568-80. doi: 10.1016/j.cell.2013.11.027

77. Huang F, Zhang J, Zhang Y, Geng G, Liang J, Li Y, et al. RNA helicase MOV10 functions as a co-factor of HIV-1 Rev to facilitate Rev/RREdependent nuclear export of viral mRNAs. Virology. (2015) 486:15-26. doi: 10.1016/j.virol.2015.08.026

78. Chang C-K, Chen C-J, Wu C-C, Chen S-W, Shih S-R, Kuo RL. Cellular hnRNP A2/B1 interacts with the NP of influenza A virus and impacts viral replication. PLoS ONE. (2017) 12:e0188214. doi: 10.1371/journal.pone.0188214

Conflict of Interest: The authors declare that the research was conducted in the absence of any commercial or financial relationships that could be construed as a potential conflict of interest.

Copyright (c) $2020 \mathrm{Su}$, Liu and Jiang. This is an open-access article distributed under the terms of the Creative Commons Attribution License (CC BY). The use, distribution or reproduction in other forums is permitted, provided the original author(s) and the copyright owner(s) are credited and that the original publication in this journal is cited, in accordance with accepted academic practice. No use, distribution or reproduction is permitted which does not comply with these terms. 